\title{
Evaluation of How Gene-Job Strain Interaction Affects Blood Pressure in the PAMELA Study
}

Cristina Menni, PhD, Vincenzo Bagnardi, PhD, Sandosh Padmanabhan, MD, PhD, Rita Facchetti, MSc, Roberto Sega, MD, Marco M. Ferrario, mD, Paolo Brambilla, MD, Wai K. Lee, PhD,

Anna F. Dominiczak, MD, FRCP, Giuseppe Mancia, MD, and Giancarlo Cesana, MD

\begin{abstract}
Objective: To see whether there is interaction between single nucleotide polymorphisms (SNPs) belonging to candidate genes for hypertension and job strain and its components (job demand and job control) in an accurately phenotyped Italian cohort (Pressioni Arteriose Monitorate E Loro Associazioni). Methods: From the Pressioni Arteriose Monitorate E Loro Associazioni cohort, we sampled 924 employed men and women who had completed a modified version of the Karasek questionnaire and for whom deoxyribonucleic acid information was available. We selected 1,510 common tagging and putative functional SNPs in 92 candidate autosomal genes involved in sympathetic nervous system, oxidative stress, renin-angiotensin-aldosterone system, and sodium balance. The interaction of each candidate SNP with the perceived job stress scores on ambulatory systolic and diastolic blood pressures was evaluated by adding product terms to a multiple regression linear model, adjusted for sex, age, total cholesterol, and body mass index. Results: Among all the SNPs tested, the interaction of SNP rs11210278 located on the endothelin 2 gene and job control was statistically significant after controlling for multiple testing, using false discovery rate (unadjusted $p=.00000661 ; p$ adjusted for false discovery rate $=.0085)$, indicating an inverse association with systolic blood pressure for the homozygous wild-type allele $(\mathrm{C} / \mathrm{C})$ and a positive association for the variant genotypes $(\mathrm{C} / \mathrm{T}$ and $\mathrm{T} / \mathrm{T})$. Conclusions: We show that the hypertensive response to job strain is present only in carriers of the rs 11210278 wild-type genotype. The phenomenon is discussed in relationship to the controversial results of field studies on job strain and hypertension. Key Words: job strain, blood pressure, candidate genes, stress perception, psychophysiology.
\end{abstract}

$\mathbf{B M I}=$ body mass index; $\mathbf{B P}=$ blood pressure; $\mathbf{C I}=$ confidence interval; DBP = diastolic blood pressure; EDN2 = endothelin 2; FDR = false discovery rate; MONICA = MONItoring CArdiovascular diseases; MOPSY = MOnica PSYchosocial; PAMELA = Pressioni Arteriose Monitorate E Loro Associazioni; SBP = systolic blood pressure; $\mathbf{S N P}=$ single nucleotide polymorphism.

\section{INTRODUCTION}

P sychosocial stress is considered to be one of the major risk factors that may contribute to the development of essential hypertension (1). Perceived work-related stress (job strain) seems to play a double role on increasing cardiovascular risk for its ubiquitous nature and long-term impact $(2,3)$. It may act indirectly by inducing unhealthy life-styles, such as smoking, reduced physical activities, increased calorie intake $(4,5)$, and/or it may act directly by affecting major regulatory systems and contributing to increase arterial pressure $(3,5,6)$.

From the Department of Statistics (C.M., V.B.), University of MilanoBicocca, Milano, Milano, Italy; BHF Glasgow Cardiovascular Research Centre (C.M., S.P., W.K.L., A.F.D.), University of Glasgow, Glasgow, UK; Division of Epidemiology and Biostatistics (V.B.), European Institute of Oncology, Milano, Italy; Study Centre on Public Health (R.F., R.S., M.M.F., G.C.) and the Department of Experimental Medicine (P.B.), University of Milano-Bicocca, Monza, Italy; and the Department of Clinical Medicine and Prevention (G.M.), University of Milano-Bicocca, San Gerardo Hospital, Monza, Italy.

Address correspondence and reprint requests to Cristina Menni, MSc, Department of Statistics, University of Milano-Bicocca, Milano, Via Bicocca degli Arcimboldi 8, 20126 Milano, Italy. E-mail: cristinamenni@gmail.com

This project was supported, in part, by the Cariplo Foundation, Italy. Work at the British Heart Foundation is funded, in part, by the British Heart Foundation Chair and Program Grant BHFPG/02/128 (A.F.D.), the Wellcome Trust Cardiovascular Functional Genomics Initiative 066780/2/012 (A.F.D.), the European Union's Sixth Framework Program InGenious HyperCare LSHM-CT-2006-037093 (A.F.D.), and Intermediate Research Fellowship FS/05/095/19937 from the British Heart Foundation (S.P.).

The authors have not disclosed any potential conflicts of interest.

Supplemental digital content is available for this article. Direct URL citations appear in the printed text, and links to the digital files are provided in the HTML text of this article on the journal's Web site www.psychosomaticmedicine.org. Received for publication June 10, 2010; revision received December 27, 2010. DOI: $10.1097 /$ PSY.0b013e318212e0be
The biological plausibility of job strain hypothesis in the genesis of hypertension is loosely confirmed in a variety of field studies. Positive findings, especially among men, have been found in several studies, using mainly ambulatory blood pressure (BP) (7-15) and the Karasek model for perceived stress (16). However, not everyone who develops hypertension reports job strain and vice versa. The traditional psychological explanation is that some people may not perceive stress because of a denial attitude, a noncomplaining tendency, or alexithymia, which unconsciously transfer anxiety into a somatic disorder (17). Another possible explanation is that job strain operates on a background of genetic susceptibility, as suggested by Imumorin et al. (18) in the gene-environment interaction model of stressinduced hypertension. Borderline significant interactions between two single nucleotide polymorphisms (SNPs) and job strain have been shown in men, both for systolic (SBP) and diastolic blood pressures (DBP) $(19,20)$.

We (21) have previously shown an association between job strain and ambulatory BP in the Pressioni Arteriose Monitorate E Loro Associazioni (PAMELA) Italian cohort. This association was also observed with clinic BP in four general population samples recruited in "Area Brianza," near Milan, Italy, as part of the World Health Organization (WHO) "MONItoring CArdiovascular diseases" (MONICA) project (22).

In this study, we tested the hypothesis that genetic variants in genes involved in pathways of BP regulation and cardiovascular risk may interact with job strain and its dimensions and, thus, influence BP.

\section{METHODS}

\section{PAMELA Study}

The PAMELA study design has been reported elsewhere (23). Briefly, 2051 people were selected randomly from the Monza population in 1991 to represent gender and age decades (25-74 years), according to the criteria used in the WHO MONICA study, conducted in the same geographic area (24). Participants were invited to come to the outpatient clinic of the local hospital (San 


\section{GENE-JOB STRAIN INTERACTION IN PAMELA STUDY}

Gerardo) in the morning of a work day (Monday through Friday) where detailed phenotypic data were collected.

The study was approved by the ethics committee of the San Gerardo Hospital in Monza, Italy. To test the SNP $\times$ job strain interaction, we selected only men and women who were employed (currently working with a stable job), who completed the MOnica PSYchosocial (MOPSY) questionnaire, and for whom deoxyribonucleic acid was available $(n=990)$. After excluding those on BPlowering treatment $(n=66)$, we had a final sample comprising 924 people. All patients were Caucasian origin.

\section{Phenotype Definitions}

Data relevant to the present study include three sphygmomanometric BP measurements with the subject in the sitting position, starting 10 minutes after the beginning of the medical visit and 24-hour ambulatory BP monitoring, using an oscillometric device (90207, Spacelabs Healthcare, Issaquah, Washington), with $\mathrm{BP}$ readings set at 20-minute intervals. After the device was checked for accuracy, the participants were sent home with instructions to participate in their usual activities and to come back the next morning for device removal. Sitting BP measures were taken before ambulatory monitoring. For the present analysis, we averaged the ambulatory SBP and DBP values for 24 hours. We concentrated on the averaged ambulatory BP measures, as those have been previously shown to better correlate with stress perception, with a similar behavior during work, leisure time, and night- "carry over effect" (25). Additional data included two home BP measurements (approximately at $7 \mathrm{AM}$ and $7 \mathrm{PM}$ ) made with a semiautomatic device (HP 5331, Philips, Andover, Massachusetts) on the arm contralateral to that used for ambulatory monitoring and three more sphygmomanometric sitting BP measurements taken after removal of the ambulatory BP device.

Information (history and physical examination) on cardiovascular risk factors, including overweight, smoking habits, serum cholesterol, blood glucose, diabetes mellitus, antihypertensive treatments, and history of previous cardiovascular morbid events, were obtained.

\section{Job Strain Assessment}

Each employed participant was asked to complete the MOPSY questionnaire, in which a short job strain scale derived from the Karasek questionnaire was included. The scale (set up at the WHO Regional Office for Europe, within the framework of the MONICA Project) was composed of 13 items, of which six items dealt with job control and five items dealt with perceived job demand (26). The remaining two items on social support were not considered for the present analysis. The Italian version of the MOPSY questionnaire was validated at the time of the first MONICA survey (27): Internal consistency (Cronbach $\alpha$ coefficient) resulted in 0.72 for job control and 0.6 for job demand; in addition, the two dimensions resulted in an orthogonal relationship, as foreseen by the model, with a Pearson correlation coefficient varying from 0.01 in men to 0.05 in women.

Job strain evaluation was obtained through the traditional quadrant term approach (28), using as cutoff points the overall sample medians of the two considered scores. The participants were classified into the low strain group (group 1) if they scored equal or below the median of the job demand scale and above the median of the job control scale. Similarly, the passive condition (group 2) was determined by scores equal or below the sample median for both dimensions; the active condition (group 3) by demand and control scores above the correspondent sample medians; and the high strain (group 4) condition by levels of job demand above the sample median and job control equal or below the sample median. In addition, according to the levels of each job strain score, participants were classified into tertile levels of job demand (cutoff points: low tertile, $<27$; medium tertile, 27-30; and high tertile, $\geq 31$ ) and job control (cutoff points: low tertile, $<69$; medium tertile, $69-75$; and high tertile, $\geq 75$ ).

\section{SNP Selection and Genotyping}

SNP selection and genotyping were done as previously described (29). We selected 1,510 common tagging and putative functional SNPs in 92 candidate autosomal genes with high biological plausibility in the development and progression of cardiovascular disease. The genes chosen were mainly involved in sympathetic nervous system, oxidative stress, renin-angiotensin-aldosterone system, and sodium balance. We selected those SNPs that tagged common variants (minor allele frequency, $\geq 0.1$ ) in the HapMap Caucasian European reference panel with $\mathrm{r}^{2} \geq 0.8$ by assessing each gene, including 10 -kb flanking region within the HapMap database (http://www.hapmap.org/). We also added to the list common potentially functional SNPs from SeattleSNPs (http://pga.gs.washington.edu/). All SNPs were tested against the predicted score of success provided by Illumina (http://www.illumina.com/), and the final selected SNPs fulfilled the following parameters - minor allele frequency, $\geq 0.05$; $\mathrm{r}^{2}, \geq 0.8$; Illumina score, $>0.6$; and no tag SNPs within $60 \mathrm{bp}$ of each other. We had a $100 \%$ coverage for all the genes selected.

The list of candidate genes, along with their functional class, chromosome location, and number of SNPs is shown in Supplemental Digital Content 1 (http://links.lww.com/PSYMED/A33). Genotyping was performed on the Illumina BeadChip platform (http://www.illumina.com/).

\section{Statistical Methods}

Quality checking included manual review of all cluster plots, genotype frequency, call rate, and deviation from Hardy-Weinberg equilibrium, using the $\chi^{2}$ test as previously described (29).

Analysis of variance and the $\chi^{2}$ test were used to compare continuous and categorical variables, respectively, between job strain quadrant term and/or genotype categories.

The interaction of each candidate SNP with the perceived job stress scores (job strain quadrant term, tertiles of job demand, tertiles of job control) on ambulatory SBP and DBP was evaluated by adding product terms to a multiple regression linear model, adjusted for the following covariates: sex, age, total cholesterol, and body mass index (BMI), using an additive model. The significant results were additionally tested with clinic and home BP readings correcting for the same covariates.

Job stress scores were treated as categorical variables. $F$ test was used to assess the significance of the interaction terms. Because testing multiple SNPs could lead to false-positive associations, we estimated the false discovery rate (FDR) and used an FDR threshold of 0.05, indicating that we should expect only $5 \%$ of the declared discoveries below this threshold to be false (30). We applied the FDR multiple testing correction to 1,324 tests for each of the $3 \times 2$ combinations of job stress and outcome variables separately to balance the loss of power that would result if we assumed independence between outcomes and/or stress dimensions. The assumption underlying the classical method of Benjamini and Hochberg (30) that we used for FDR could lead to very conservative inference, as it assumes that all the hypotheses tested are independent or weakly correlated. In our study, the independence assumption could be considered true for the very great majority of the 1,324 SNPs tested, but it does not apply to the two outcome measures (SBP and DBP) and/or to the three job stress dimensions (job control score, job demand score, and job strain quadrant).

\section{RESULTS}

The characteristics of the PAMELA study subjects included in this analysis are presented in Table 1. Men accounted for $62 \%$ of the total cohort. Participants scored above the sample median of the demand scale (ie, high strain + active quadrants) were younger than those who scored below the median (ie, low strain + passive quadrants), both in men $(p=.02)$ and in women $(p=.006)$. In women, BMI and total cholesterol were significantly different across stress perception categories. In our study sample, ambulatory SBP and ambulatory DBP did not differ significantly between stress perception categories, both in men $(p=.38$ for ambulatory SBP; $p=.99$ for ambulatory DBP) and in women ( $p=.76$ for SBP; $p=.61$ for ambulatory DBP). The same was observed for all the clinic and home readings.

As previously reported (29), of the 1,510 autosomal SNPs selected, after quality control, 105 were excluded because of poor clustering, 55 were excluded because of Minor Allele Frequency $<0.01,26$ were excluded because of deviation from Hardy-Weinberg equilibrium; for the final analysis, 1,324 (86\%) SNPs were included. Genotyping was successful in $99.48 \%$ of individuals. 


\section{MENNI et al.}

TABLE 1. Participant Characteristics by Stress Perception Category and Sex $(n=924)$

\begin{tabular}{|c|c|c|c|c|c|}
\hline & \multicolumn{4}{|c|}{ Stress Perception } & $p$ \\
\hline Men, $n$ & 156 & 154 & 166 & 97 & \\
\hline Age, years & $45.1(9.9)$ & $42.5(10.4)$ & $44.6(11.1)$ & $41.6(9.7)$ & .02 \\
\hline Body mass index, $\mathrm{kg} / \mathrm{m}^{2}$ & $26(3.8)$ & $25.4(3.5)$ & $25.3(3.3)$ & $25.9(3.7)$ & .24 \\
\hline Total cholesterol, mg/dL & $223.7(41.3)$ & $218.8(45.6)$ & $215.7(45.2)$ & $215.4(41.1)$ & .34 \\
\hline Current smokers, $n(\%)$ & $54(34.6)$ & $50(32.5)$ & $66(39.8)$ & $36(37.1)$ & .57 \\
\hline Current alcohol drinkers, $n(\%)$ & $101(64.7)$ & $97(63.4)$ & $107(64.5)$ & $61(63.5)$ & .99 \\
\hline Ambulatory SBP, mm Hg & $120.7(10.2)$ & $120(10.1)$ & $121.5(10.2)$ & $121.9(9.2)$ & .38 \\
\hline Ambulatory DBP, mm Hg & $76.2(7.2)$ & $76.1(6.3)$ & $76.3(7.1)$ & $76.1(6.9)$ & .99 \\
\hline Clinic SBP, mm Hg & $128.4(16.3)$ & $126.5(14.7)$ & $129.7(16.8)$ & $128.2(14.4)$ & .59 \\
\hline Women, $n$ & 77 & 55 & 130 & 89 & \\
\hline Age, years & $42.5(10.4)$ & $38.6(9.9)$ & $41.2(10.1)$ & $37.6(9.0)$ & .006 \\
\hline Body mass index, $\mathrm{kg} / \mathrm{m}^{2}$ & $24.7(4.6)$ & $23.8(3.7)$ & $23(3.3)$ & $24(5.1)$ & .03 \\
\hline Total cholesterol, mg/dL & $218.8(53.9)$ & $210.7(47.2)$ & $210.2(34.5)$ & $198(42)$ & .02 \\
\hline HDL cholesterol, mg/dL & $61.9(16.9)$ & $58.3(16)$ & $63.4(13.4)$ & $61.6(14.7)$ & .20 \\
\hline Serum triglyceride, $\mathrm{mg} / \mathrm{dL}$ & $88.5(43.9)$ & $85(56)$ & $76.8(38.1)$ & $74.7(42.3)$ & .13 \\
\hline Current smokers, $n(\%)$ & $22(28.6)$ & $14(25.5)$ & $33(25.4)$ & $22(24.7)$ & .95 \\
\hline Current alcohol drinkers, $n(\%)$ & $27(35.1)$ & $17(30.9)$ & $33(25.4)$ & $29(32.9)$ & .45 \\
\hline Ambulatory SBP, mm Hg & $114.7(10.5)$ & $114.3(7.7)$ & $113.4(9.8)$ & $114.3(8.3)$ & .76 \\
\hline Ambulatory DBP, $\mathrm{mm} \mathrm{Hg}$ & $71.6(7.1)$ & $71.8(6.7)$ & $70.7(6)$ & $71.3(5.9)$ & .61 \\
\hline Clinic SBP, mm Hg & $122.2(18.1)$ & $116.6(14.4)$ & $119.9(17.4)$ & $118.2(14.2)$ & .24 \\
\hline
\end{tabular}

Data are reported as mean (standard deviation) values.

$\mathrm{HDL}=$ high-density lipoprotein; SBP = systolic blood pressure; $\mathrm{DBP}=$ diastolic blood pressure.

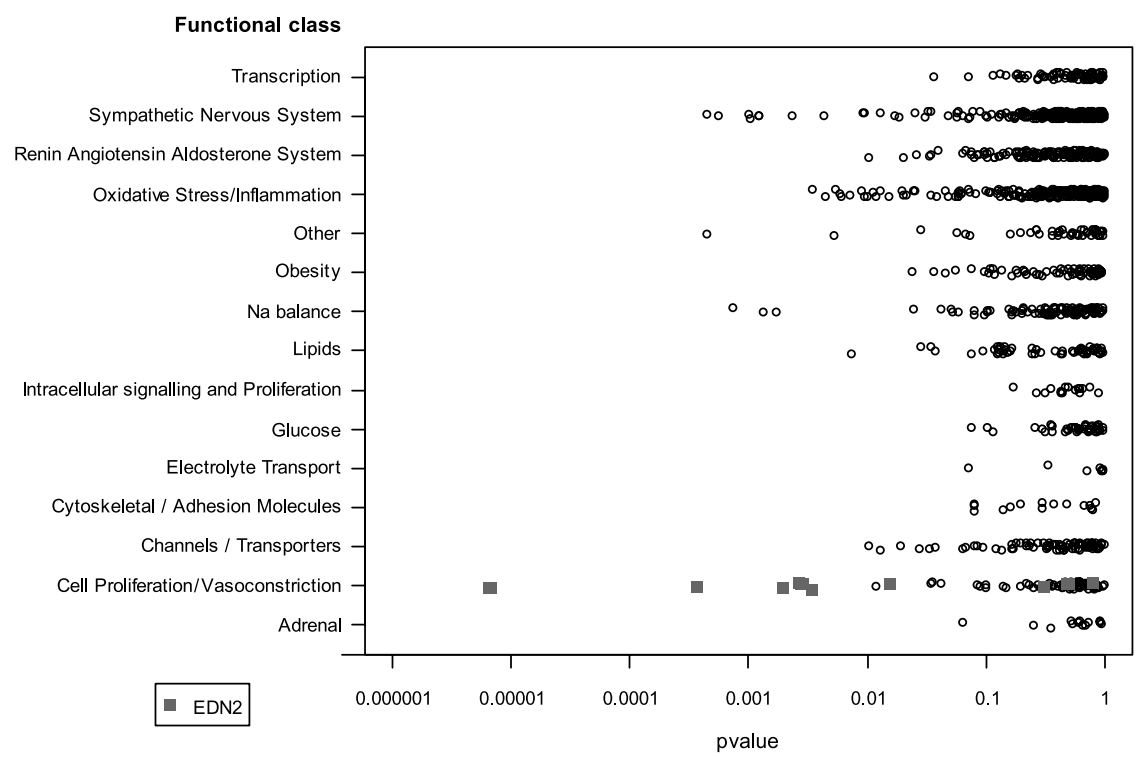

Figure 1. Plot of the $p$ values from the $F$ test measuring single nucleotide polymorphism (SNP)-job control interaction effect on ambulatory systolic blood pressure, by genetic functional class. The 11 SNPs on endothelin 2 (EDN2) gene are marked with red squares. Na= sodium. 


\section{GENE-JOB STRAIN INTERACTION IN PAMELA STUDY}

TABLE 2. Ambulatory SBP and DBP Adjusted Means by rs11210278 Genotype and Job Control Levels

\begin{tabular}{|c|c|c|c|c|c|}
\hline rs11210278 Genotype & Job Control (Score Tertiles) & \multicolumn{2}{|c|}{ Ambulatory SBP } & \multicolumn{2}{|c|}{ Ambulatory DBP } \\
\hline \multirow{2}{*}{ Wild-type (C/C) } & Medium $(n=245)$ & 118.6 & $117.5-119.8$ & 74.5 & $73.7-75.3$ \\
\hline & High $(n=160)$ & 115.9 & $114.5-117.3$ & 73.1 & $72.2-74.1$ \\
\hline Heterozygous $(\mathrm{C} / \mathrm{T})$ & Low $(n=87)$ & 117.1 & $115.6-118.7$ & 73.9 & $72.9-74.9$ \\
\hline \multirow[t]{3}{*}{ Homozygous mutant $(\mathrm{T} / \mathrm{T})$} & $\operatorname{Low}(n=15)$ & 114.8 & 111.7-117.9 & 73.2 & $71.1-75.3$ \\
\hline & Medium $(n=13)$ & 118.8 & $115.7-121.9$ & 74.6 & $72.4-76.7$ \\
\hline & High $(n=12)$ & 124.5 & $121.2-127.9$ & 77.9 & $75.6-80.2$ \\
\hline Interaction $p$ value ${ }^{b}$ & & 0.00000661 & & 0.0031 & \\
\hline
\end{tabular}

${ }^{a}$ Adjusted for age, sex, body mass index, and total cholesterol in a multiple linear regression model. Adjusted means are evaluated at the mean level of the adjusting covariates.

${ }^{b}$ Interaction in multiple linear regression model was defined as the product terms of the dummy independent variables: tertile of job control (Low, Medium, or High) and genotype (coded as an ordinal variable with levels 1,2,3). The $p$ value is based on the $F$ test (2 days) for the interaction between job control and genotype. $\mathrm{SBP}=$ systolic blood pressure; $\mathrm{DBP}=$ diastolic blood pressure; $\mathrm{CI}=$ confidence interval.

Figure 1 shows the $p$ values from the $F$ test measuring SNPjob control interaction effect by genetic functional class. When studying ambulatory SBP, the only interaction with an FDR of $<5 \%$ was found for SNP rs11210278 on the intronic region of the endothelin 2 (EDN2) gene on chromosome 1 and job control score (unadjusted $p=.00000661 ; p$ adjusted for FDR $=$ .0085). This association remains borderline significant if we use an FDR correction for all the $1324 \times 2 \times 3=7944$ tests ( $p$ adjusted for FDR $=.0525$ ). Even though only the interaction of SNP rs11210278 and job control result was significant after multiple testing correction, we saw a trend for 6 of the remaining 10 SNPs on gene EDN2 that passed quality checking (Fig. 1).

No significant interactions were found for job strain quadrant term and job demand score. When studying ambulatory DBP, we did not find any interactions with an FDR of $<5 \%$.

Main effects on ambulatory SBP values estimated, using a multiple linear regression model, are shown in Supplemental Digital Content 2 (http://links.lww.com/PSYMED/A34). Table 2 summarizes the effects of job strain on ambulatory BP levels by rs11210278 genotype. After adjustment for age, sex, BMI, and total cholesterol, we found a significant decrease in ambulatory $\mathrm{SBP}$ with increasing job strain in individuals with the $\mathrm{C} / \mathrm{C}$ genotype and an increase in those with $\mathrm{C} / \mathrm{T}$ and $\mathrm{T} / \mathrm{T}$ genotypes.

Figure 2 shows the EDN2 gene with all the SNPs tested, the LD blocks and the interaction $p$ values. As shown in Figure 3, stratification by gender did not alter the association. We found similar results with clinic and home SBP measurements (clinic $\mathrm{SBP}$, unadjusted $p=.00498$; home SBP, unadjusted $p=$ .00159). A similar pattern was observed for ambulatory DBP (unadjusted $p=.00310$ ).

\section{DISCUSSION}

The main finding of this study is that there is a statistically significant interaction for ambulatory SBP between job control
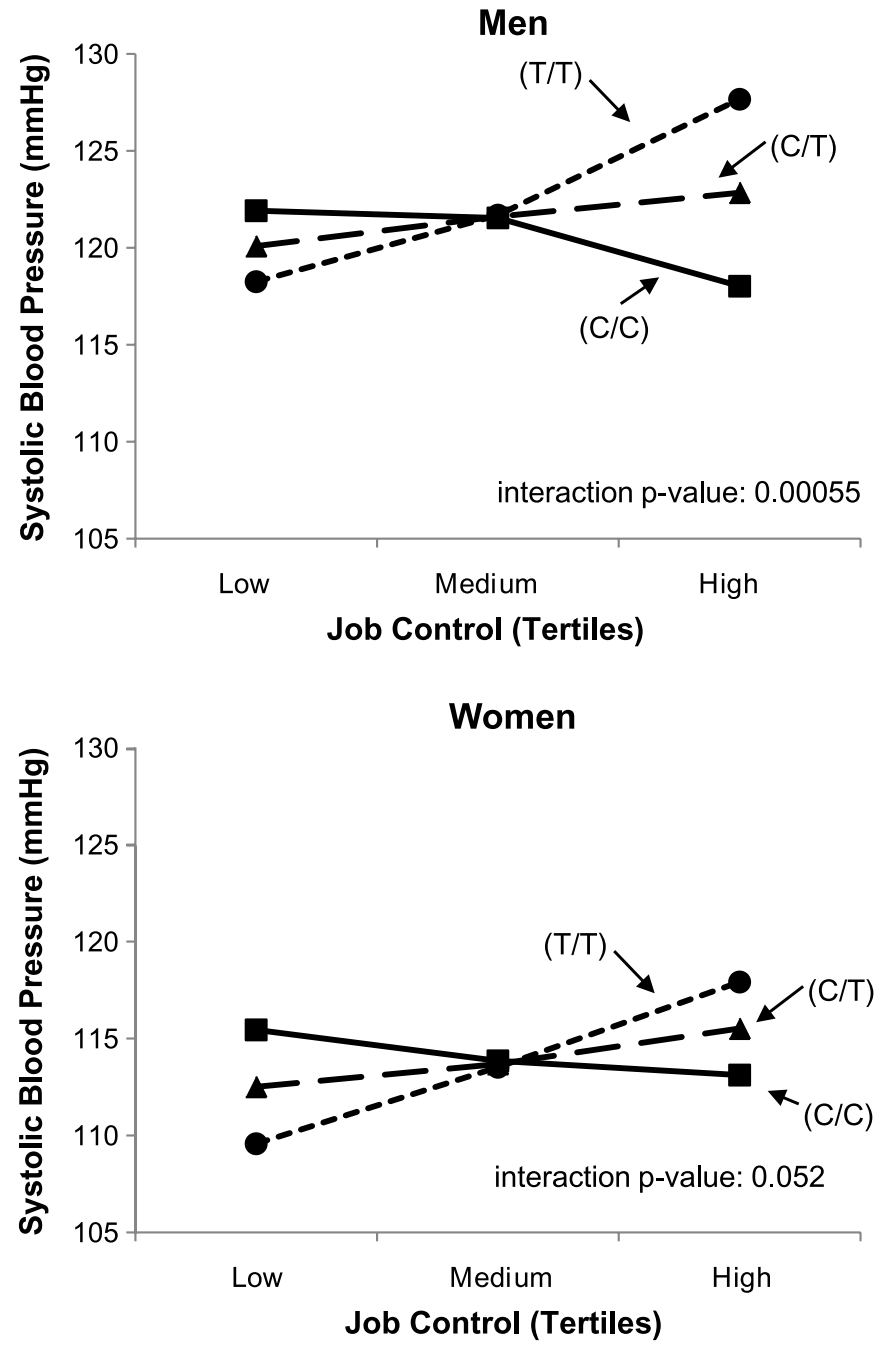

Figure 2. LD plot for the endothelin 2 gene and interaction $p$ values from the $F$ test measuring single nucleotide polymorphism-job control interaction. 


\section{MENNI et al.}

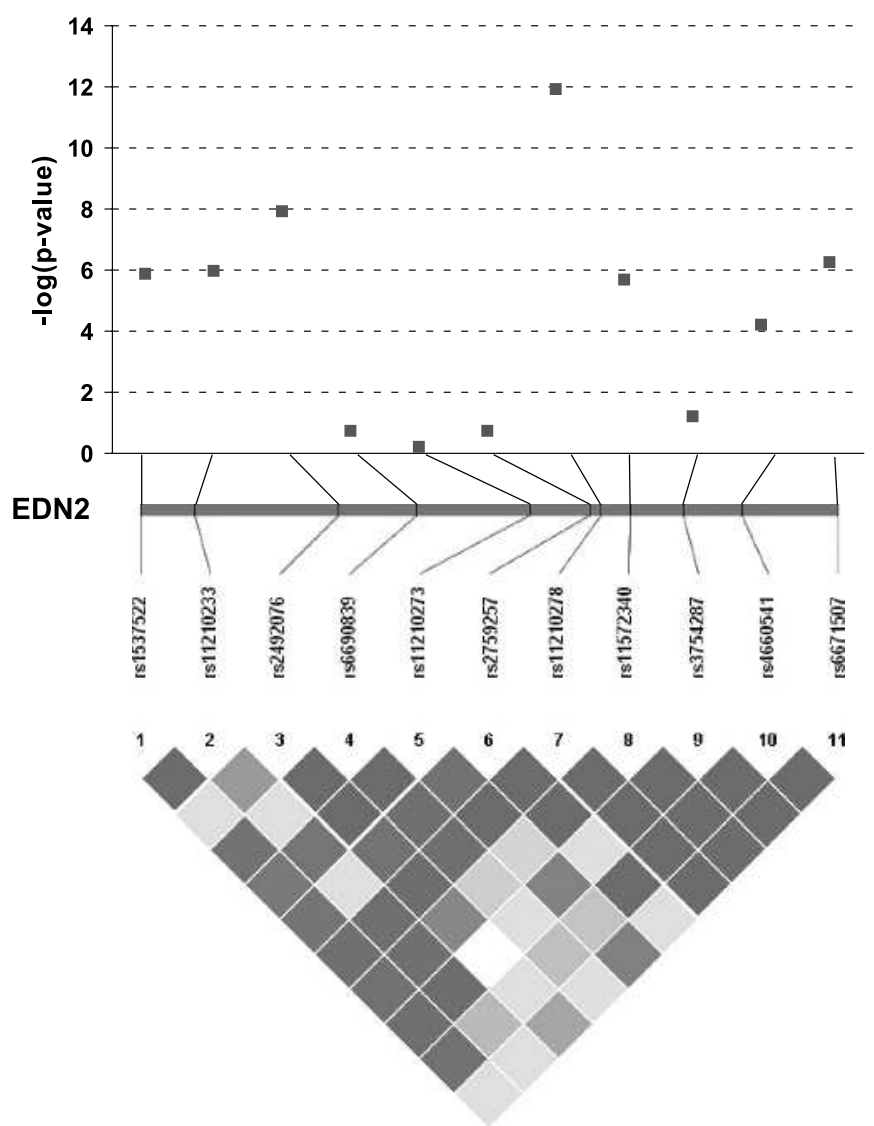

Figure 3. Interaction plot of the estimated ambulatory systolic blood pressure levels according to job control tertile and rs1210278 genotype by gender. $E D N 2=$ endothelin 2

and SNP rs1 121078 located in the intronic region of the EDN2 gene on chromosome 1 . This result is confirmed when studying men and women separately and is further validated when looking at clinic and home readings and correcting for the same covariates.

Job strain has been prospectively linked to an increase of BP because of its "control" dimension $(9,32)$, so our finding is in line with the existing literature. It has been argued that low control is typical of jobs characterized by poor content and less remuneration, which are common among people of low socioeconomic status. This could imply that low job control does not reflect only an unsatisfactory workplace and interpersonal relationship at work but is rather an index of a more complex social discomfort produced by the interplay of work with variables like education, income, housing, and others (33). In addition, the pattern of response and significance is similar in men and women. This represents a new finding, as the latter group does not usually show significant BP responses associated with the job content scales $(10,15)$.

The endothelial system has been proposed as a mediator of the effect of job strain (18). The EDN2 gene is located on chromosome 1p34 and belongs to a family of highly potent vasoconstrictive peptides (EDN1 on chromosome 6p24, EDN3 on chromosome 20q13). EDN2 encodes a preproprotein, which is processed to a short mature form that functions as a ligand for the endothelin receptors. Endothelin receptors are widely expressed in all tissues, including nonvascular structures like epithelial cells, glia, and neurons. The principal physiological role of endothelin receptors is the maintenance of vascular tone, comitogenic activity, and potentiating the effects of other growth factor, such as platelet-derived growth factor (34). Imumorin et al. (18) suggested that the role of the behavioral stress is pivotal in mediating the adverse effects of the endothelin genes on vascular function.

Carriers of the $\mathrm{C} / \mathrm{C}$ genotype (homozygous wild-type) respond to an increase in stress perception with an expected increase in ambulatory SBP, whereas both heterozygous and homozygous mutant $(\mathrm{C} / \mathrm{T}$ and $\mathrm{T} / \mathrm{T})$ respond with a decrease. Having a copy of the $\mathrm{T}$ allele cannot simply be considered as protective in stress susceptibility because both heterozygous and homozygous mutant show an increase of BP as stress perception decreases. Such a response is very similar to what is psychologically known as denial, mentioned in the Introduction as a noncomplaining tendency with somatization. Our results suggest that denial might have - in addition to psychologicalgenetic components, which influence reciprocally each other, making the biology of the stress phenomenon not understandable without a deeper analysis.

Genetic predisposition plays a role in BP regulation. It is estimated that around $30 \%$ of variation in $\mathrm{BP}$ is due to genetic factors (35) and that BP is more closely correlated in monozygotic, rather than dizygothic, twins (36). Also, there are individual differences in stress response stereotypy, in which BP increase is a frequent expression (9). Since 1957 (37), different stress exposure has been demonstrated to produce different cognitive emotional response, to which, in rats, a behaviorally induced gene expression seems to correspond (38). In our population study, the genetic component associated with BP increase does not regard a central nervous system expression but a peripheral mechanism (cell proliferation/vasoconstriction). A possible hypothesis is that the peripheral mechanism in the variant genotype of the EDN2 gene is induced, almost as compensation, by the inability to appreciate stress adequately, which has, at least initially, a positive function in the adaptive process (39). Further research and replications are needed to evaluate this hypothesis and many others that can be suggested as regard the relationship between the perception of the environment and the peripheral control of a fundamental physiological function like BP.

Our study has many strengths. First, the PAMELA study is a large sample of an extensively phenotyped general population that enables studies of gene and environmental effects and allows us to account for several potential confounders (eg, BMI, total and high-density lipoprotein cholesterol, smoking, and alcohol consumption). We selected a set of genes with high biological plausibility in cardiovascular traits and selected SNPs that tagged all variants in the genes and their flanking $10-\mathrm{kb}$ regions (40).

Our study has some limitations. First, because of the crosssectional nature of the study design, no inferences can be made with respect to causation. Second, for the same reason, we did 
not have a time dimension to control for prolonged exposure to job strain. Third, we had to exclude those who did not work or had retired during the study; this exclusion reduced our sample size. Finally, we recognize that power is a major issue in the testing of gene-environment interactions, and our study was underpowered. However, this is an exploratory analysis. We think that our result is novel and interesting, as it provides new insights into how environmental factors, such as job strain, can influence gene-phenotype associations.

The next step would be to validate our result with replication on multiple independent samples. Still, the lack of many large epidemiological studies, which include both a measure of job strain and genotypic data, makes replication challenging.

\section{REFERENCES}

1. Beilin LJ, Puddey IB, Burke V. Lifestyle and hypertension. Am J Hypertens 1999;12:934-45.

2. Kivimaki M, Leino-Arjas P, Luukkonen R, Riihimaki H, Vahtera J, Kirjonen J. Work stress and risk of cardiovascular mortality: prospective cohort study of industrial employees. BMJ 2002;325:857.

3. Lucini D, Riva S, Pizzinelli P, Pagani M. Stress management at the worksite: reversal of symptoms profile and cardiovascular dysregulation. Hypertension 2007;49:291-7.

4. Berkman LF. Tracking social and biological experiences: the social etiology of cardiovascular disease. Circulation 2005;111:3022-4.

5. McEwen BS. Protective and damaging effects of stress mediators. N Engl J Med 1998;338:171-9.

6. Rozanski A, Blumenthal JA, Davidson KW, Saab PG, Kubzansky L. The epidemiology, pathophysiology, and management of psychosocial risk factors in cardiac practice: the emerging field of behavioral cardiology. $\mathrm{J}$ Am Coll Cardiol 2005;45:637-51.

7. Schnall PL, Schwartz JE, Landsbergis PA, Warren K, Pickering TG. A longitudinal study of job strain and ambulatory blood pressure: results from a three-year follow-up. Psychosom Med 1998;60:697-706.

8. Schnall PL, Landsbergis PA, Baker D. Job strain and cardiovascular disease. Annu Rev Public Health 1994;15:381-411.

9. Pickering T. The effects of occupational stress on blood pressure in men and women. Acta Physiol Scand Suppl 1997;640:125-8.

10. Ohlin B, Berglund G, Rosvall M, Nilsson PM. Job strain in men, but not in women, predicts a significant rise in blood pressure after 6.5 years of follow-up. J Hypertens 2007;25:525-31.

11. Theorell T, Karasek RA. Current issues relating to psychosocial job strain and cardiovascular disease research. J Occup Health Psychol 1996;1: 9-26.

12. Landsbergis PA, Schnall PL, Pickering TG, Warren K, Schwartz JE. Lifecourse exposure to job strain and ambulatory blood pressure in men. Am J Epidemiol 2003;157:998-1006.

13. Kawakami N, Haratani T, Araki S. Job strain and arterial blood pressure, serum cholesterol, and smoking as risk factors for coronary heart disease in Japan. Int Arch Occup Environ Health 1998;71:429-32.

14. Kang MG, Koh SB, Cha BS, Park JK, Baik SK, Chang SJ. Job stress and cardiovascular risk factors in male workers. Prev Med 2005;40:583-8.

15. Guimont C, Brisson C, Dagenais GR, Milot A, Vezina M, Masse B, Moisan J, Laflamme N, Blanchette C. Effects of job strain on blood pressure: a prospective study of male and female white-collar workers. Am J Public Health 2006;96:1436-43.

16. Karasek RA. Job demands, job decision latitude and mental strain: implication for job redesign. Administrative Science Quarterly 1979;24: 285-307.

17. Greiner BA, Krause N, Ragland D, Fisher JM. Occupational stressors and hypertension: a multi-method study using observer-based job analysis and self-reports in urban transit operators. Soc Sci Med 2004;59:1081-94.

18. Imumorin IG, Dong Y, Zhu H, Poole JC, Harshfield GA, Treiber FA, Snieder H. A gene-environment interaction model of stress-induced hypertension. Cardiovasc Toxicol 2005;5:109-32.
19. Ohlin B, Berglund G, Nilsson PM, Melander O. Job strain, decision latitude and alpha2B-adrenergic receptor polymorphism significantly interact, and associate with higher blood pressures in men. J Hypertens 2007;25: 1613-9.

20. Ohlin B, Berglund G, Nilsson PM, Melander O. Job strain, job demands and adrenergic beta1-receptor-polymorphism: a possible interaction affecting blood pressure in men. J Hypertens 2008;26:1583-9.

21. Cesana G, Ferrario M, Sega R, Milesi C, De VG, Mancia G, Zanchetti A. Job strain and ambulatory blood pressure levels in a population-based employed sample of men from northern Italy. Scand J Work Environ Health 1996;22:294-305.

22. Cesana G, Sega R, Ferrario M, Chiodini P, Corrao G, Mancia G. Job strain and blood pressure in employed men and women: a pooled analysis of four northern italian population samples. Psychosom Med 2003;65:558-63.

23. Mancia G, Sega R, Bravi C, De Vito G, Valagussa F, Cesana G, Zanchetti A. Ambulatory blood pressure normality: results from the PAMELA study. J Hypertens 1995;13:1377-90.

24. The World Health Organization MONICA Project (monitoring trends and determinants in cardiovascular disease): a major international collaboration. WHO MONICA Project Principal Investigators. J Clin Epidemiol 1988;41:105-14.

25. Belkic KL, Landsbergis PA, Schnall PL, Baker D. Is job strain a major source of cardiovascular disease risk? Scand J Work Environ Health 2004; 30:85-128.

26. WHO Regional Office for Europe. MONICA psychosocial optional study: MOPSY suggested measurement and instruments. Copenhagen: WHO Regional Office for Europe, draft 3037H MRC; 1988.

27. Cesana G, Poncato E, Duzioni F. Indagine pilota sulla affidabilità di un questionario per lo studio dei fattori psico-socio-occupazionali in relazione alla insorgenza di coronaropatia. Arch Sci Lav 1987;3:151-70.

28. Landsbergis PA, Schnall PL, Warren K, Pickering TG, Schwartz JE. Association between ambulatory blood pressure and alternative formulations of job strain. Scand J Work Environ Health 1994;20:349-63.

29. Padmanabhan S, Menni C, Lee WK, Laing S, Brambilla P, Sega R, Perego R, Grassi G, Cesana G, Delles C, Mancia G, Dominiczak AF. The effects of sex and method of blood pressure measurement on genetic associations with blood pressure in the PAMELA study. J Hypertens 2010;28:465-77.

30. Benjamini Y, Hochberg Y. Controlling the false discovery rate: a practical and powerful approach to multiple testing. J R Statis Soc B 1995;57: 289-300.

31. Lu X, Perkins DL. Re-sampling strategy to improve the estimation of number of null hypotheses in FDR control under strong correlation structures. BMC Bioinformatics 2007;8:157.

32. Steptoe A, Willemsen G. The influence of low job control on ambulatory blood pressure and perceived stress over the working day in men and women from the Whitehall II cohort. J Hypertens 2004;22:915-20.

33. Marmot MG, Bosma H, Hemingway H, Brunner E, Stansfeld S. Contribution of job control and other risk factors to social variations in coronary heart disease incidence. Lancet 1997;350:235-9.

34. NCBI Entrez Gene. Gene ID 1907. Available at http://www.ncbi.nlm.nih. gov/gene/1907?ordinalpos=2\&itool=EntrezSystem2.PEntrez.Gene.Gene_ ResultsPanel.Gene_RVDocSum. 2010. Accessed December 15, 2010.

35. Beevers G, Lip GY, O'Brien E. ABC of hypertension: the pathophysiology of hypertension. BMJ 2001;322:912-6.

36. Luft FC. Twins in cardiovascular genetic research. Hypertension 2001;37: $350-6$.

37. Levine S. Infantile experience and resistance to physiological stress. Science 1957;126:405.

38. Meaney MJ, Bhatnagar S, Diorio J, Larocque S, Francis D, O'Donnell D, Shanks N, Sharma S, Smythe J, Viau V. Molecular basis for the development of individual differences in the hypothalamic-pituitary-adrenal stress response. Cell Mol Neurobiol 1993;13:321-47.

39. Cesana G, Menni C. Cardiovascular risk as a paradigm of the negative consequences of stress at work: a "conflicting evidence." In: Sher L, editor. Psychological Factors and Cardiovascular Disorders: The Role of Stress and Psychosocial Influences. Hauppauge, New York: Nova Science Publishers; 2009.

40. Padmanabhan S, Melander O, Hastie C, Menni C, Delles C, Connell JM, Dominiczak AF. Hypertension and genome-wide association studies: combining high fidelity phenotyping and hypercontrols. J Hypertens 2008; $26: 1275-81$ 